\title{
Artículo Especial: Manejo de la alopecia androgenética en las mujeres desde una perspectiva del curar de y las creencias
}

\author{
Management of androgenetic alopecia in women from the perspective of "caring of" and beliefs
}

Esteban Rubinstein ${ }^{\ddagger}$

\begin{abstract}
Resumen
Mediante dos viñetas clínicas de pacientes con alopecia, el autor de este artículo: 1) describe la evidencia que sustenta los diferentes abordajes de las mujeres con patrón femenino de pérdida de cabello y la complejidad del acceso a la información según las distintas perspectivas de atención médica; 2) propone (citando a Heidegger) el verbo "curar de" para representar el acto de ocuparse o interesarse por los problemas de los pacientes, como una alternativa superadora a los términos "manejar" (por su connotación que remeda el control o la manipulación) o "proveer cuidados médicos" (por su connotación vinculada a la gestión de los sistemas de salud; 3) abre la discusión sobre las creencias de los médicos en relación con sus actos, incluso aquellos basados en la medicina "científica" oficial, actualmente hegemónica en Occidente.
\end{abstract}

\section{Abstract}

Using two clinical vignettes of patients with alopecia, the author of this article: 1) describes the evidence supporting the different approaches of women with female pattern hair loss and the complexity that embeds the access to the information based on different perspectives; 2) proposes (quoting Heidegger) to use the verb " to care for" to represent the act of becoming interested with patients' problems, as a better alternative to the verb "to manage" (because of its connotation of control and manipulation) or "to provide medical care" (because of its connotation linked to the management of health systems); 3) opens the discussion about physicians' beliefs related to their acts, including those based on "scientific" official, currently hegemonic medicine in the West.

Palabras clave: alopecia androgenetica, creencias, manejo, cuidados de la salud, filosofía. Key words: androgenetic alopecia, beliefs , management, health care , philosophy

Rubinstein E. Manejo de la alopecia androgenética en las mujeres desde una perspectiva del curar de y las creencias. Evid Act Pract Ambul. 2015;18(2):50-61. Abr-Jun.

Una consulta puntual, en una mañana luminosa de abril como la de hoy, puede quedar ahí, en el instante de ese encuentro, o seguir dando vueltas hasta llegar a otra instancia, como la escritura, en este caso. La señora Ofelia J, de 82 años, ya había despertado en mí el deseo de tener algo escrito acerca de ella ya que dos meses atrás le pedí que me describiera sus vacaciones mientras yo transcribía lo que me contaba (ese texto quedó guardado, dispuesto a aparecer, tal vez, en algún lado).

Me gusta el modo en que Ofelia cuida de su vida, podría decir que empuña su existencia y la disfruta; y a mí me place atenderla. La acompaño como su médico desde hace casi veinte años. En ese entonces comencé a atender a ella y a sus dos hermanas; eran tres mujeres de unos 60 años, alegres y simpáticas, con quienes siempre nos hemos reído mucho en el consultorio. La hermana más joven murió tempranamente de un cáncer de pulmón que diagnostiqué con dolor, como siempre que uno tiene que dar malas noticias. La hermana mayor desarrolló enfermedad de Alzheimer a los 70 años y falleció por un accidente cerebrovascular; su fin fue triste, pero tuvo una linda vida. Las tres hermanas $\mathrm{J}$ siempre me cayeron muy bien. Con Ofelia casi nunca hablamos de sus hermanas muertas, a quienes quiso mucho. Sus problemas de salud son los siguientes: hipotiroidismo e hipertensión arterial controlados y en tratamiento, una banda monoclonal estable, que nunca requirió tratamiento y que diagnosticó la hematóloga cuando yo le envié a la paciente a partir de una eritrosedimentación elevada (alrededor de 80) que le había aparecido unos cinco años antes, en el marco de un cuadro febril inespecífico que remitió espontáneamente. Recuerdo que seguí durante un año ese valor alterado y que un día le planteé a la paciente que teníamos dos opciones: o dejar tranquila a esa eritro elevada, o profundizar los estudios para ver si encontrábamos una posible causa, dándole mi opinión de que no pensaba que hacerlo le aportaría un beneficio terapéutico y que probablemente no encontraríamos una patología que explicara ese hallazgo. Ella prefirió intentar saber por qué tenía alta la eritro y entonces comencé haciendo una consulta a hematología y mi colega encontró esa banda monoclonal, que explicó, de algún modo, la alteración de la eritrosedimentación, que se ha mantenido estable y sin requerir tratamiento. La paciente también tuvo cáncer de mama, diagnosticado hace 28 años a partir de una mamografía: se le realizó una mastectomía izquierda y desde entonces no volvió a tener imágenes patológicas ni nódulos palpables en la mama contralateral.
Ofelia vive sola, tiene un hijo de 54 años que está separado y que no tuvo hijos, trabajó como administrativa en una empresa y desde que se jubiló se ocupa de su casa, hace yoga, sale a dar unas vueltas al parque, visita a sus amigas y de vez en cuando se encuentra con su familia (hijo y sobrinos). Podríamos decir que es una mujer sana, en el sentido de que está asintomática y no sufre ninguna enfermedad. Sin embargo, toma contacto frecuentemente con los médicos, realizando un promedio de diez consultas anuales. Visita una o dos veces al año por su hipotiroidismo al endocrinólogo (este también le da calcio y vitamina $\mathrm{D}$ ), al especialista de mama para sus controles, a la hematóloga por la banda monoclonal y al cardiólogo por la hipertensión (lo conoció hace quince años cuando yo se la envié por un síntoma dudoso de angina de pecho y luego Ofelia quiso seguir controlando su hipertensión con él). A mí me ve unas dos o tres veces por año, ya sea para tenerme al tanto de su salud, para hacer un control o para consultarme por temas puntuales, tales como lumbalgia, diarrea, dolor de hombro, alopecia, fiebre, tos, síncope, verrugas, eccema microbiano y otalgia. También durante un tiempo la ayudé a bajar de peso; tenía una obesidad importante y finalmente logró llegar a un peso adecuado con la ayuda de PROSAHI, un grupo terapéutico que existe en el Hospital y que ahora se llama Bajando de peso.

A continuación quisiera transcribir la evolución que escribí en la historia clínica después de una visita que me hizo Ofelia hace un año, simplemente con el objetivo de intentar describir la música y el clima de las consultas y del vínculo que tiene conmigo: Viene a contarme las novedades. Está asintomática y se encuentra muy bien. Tiene 81 años y los lleva bien y contenta. Charlamos sobre las decisiones compartidas y tiene muy claro que ella toma decisiones y se siente muy bien tratada y contenida por la hematóloga, el cardiólogo, el endocrinólogo y por mí. Me interesa describir este clima ya que podría ser evaluado, desde una perspectiva crítica, como un modelo de atención lindante con la "sobremedicalización". De algún modo eso podría ser cierto, ya que se trata de una mujer mayormente asintomática, que ha venido realizando durante estos últimos quince años aproximadamente diez consultas médicas al año y que utiliza recursos del médico de familia y de los especialistas que alguien podría argüir que podrían destinarse a pacientes más enfermos; sin embargo, me dieron ganas de describir el patrón de consultas de Ofelia para que nos permitamos reflexionar acerca de en qué medida el tema de la 
sobremedicalización no puede discutirse ni pensarse como un asunto simple, sino complejo, como casi todos los problemas que atañen a la medicina familiar y a gran parte de la práctica médica. En resumen: opino que si bien desde el punto de vista técnico (o teórico) Ofelia podría estar "sobremedicalizada", la paciente se siente contenida por el sistema de atención médica que ha ido eligiendo a lo largo de su vida, dicho sistema está en condiciones de contenerla y a sus integrantes les da placer hacerlo (por lo menos a mí, y muy probablemente a mis colegas también).

Volvamos ahora a esta mañana luminosa de abril. Hoy Ofelia vino a verme para conocer mi opinión acerca de un tratamiento que le indicó una dermatóloga a la que visitó por su cuenta (cuando digo "por su cuenta" me refiero a que me había pedido la derivación por el sistema de mensajes y yo se la extendí, sin preguntarle para qué iba a ver a un dermatólogo —este comentario está relacionado con un modelo específico de atención ambulatoria que tenemos en el Plan de Salud del Hospital Italiano en el que el médico de cabecera consulta o deriva a sus pacientes con el especialista mediante una derivación electrónica-). La cuestión es que Ofelia consultó a esta dermatóloga por su alopecia. He aquí lo que escribió mi colega en la historia clínica: alopecia, patrón femenino de larguísima data, ludwig 3, finasteride y minoxidil.La consulta de hoy conmigo podría catalogarse como sencilla si alguien lee lo que escribí en la historia clínica: Viene a conocer mi opinión acerca de tomar finasteride para la alopecia, droga indicada por una dermatóloga a la que consultó. Leyó en el prospecto que podría traer cáncer de mama y ella le tiene miedo a esta enfermedad. Charlamos. Doy ejemplo con la pared del consultorio. Prefiere no tomar. Pese a haber sido una consulta relativamente breve (duró quince minutos) y sobre un tema puntual y específico, yo considero que fue compleja, como la mayoría de los encuentros del médico de familia con sus pacientes. Mi objetivo es reflexionar ahora acerca de lo que ha ocurrido esta mañana y de algunas ideas que me han surgido y que están relacionadas con la complejidad del trabajo del médico de familia y de la medicina en general.

Describiré a continuación qué ocurrió en esos quince minutos en los que estuve hoy con ella: no hubo mucha charla previa (hablar de la vida en general, etc.) y tras los saludos afectuosos Ofelia fue directamente al grano: me contó que había consultado con una dermatóloga para ver si había algo nuevo para su alopecia y que ella le había dado un medicamento (me muestra la caja del finasteride), pero que antes de comenzar a tomarlo leyó en el prospecto que podía causar cáncer de mama y entonces pidió un turno conmigo para conocer mi opinión. Yo le dije que el riesgo de desarrollar cáncer de mama a causa del finasteride era bajísimo y que podía tomarlo sin problema, pero que tal vez el tema más importante sobre el cual podía asesorarla estaba relacionado con que la eficacia de la droga para mejorar la alopecia androgenética de larga data en las mujeres es muy baja. Ofelia me explicó que la dermatóloga le había advertido eso, pero que ella tenía ganas de intentarlo. Le dije que probara, y ella volvió a traer el tema del temor a desarrollar nuevamente cáncer de mama ya que había sufrido mucho con esa enfermedad. Entonces la miré, le pedí que cerrara los ojos y le pregunté: ¿En qué estado están, a su juicio, las paredes de este consultorio? Se sorprendió y contestó: Bien, están muy bien. Luego le pedí que abriera los ojos, miró las paredes, advirtió las dos enormes manchas de humedad, sonrió y me dijo: No me había dado cuenta. Yo aproveché y le dije: Si usted no me hubiera mencionado el tema de su cabello yo no me habría dado cuenta de su leve alopecia. Y es cierto. Si bien la dermatóloga le otorgó un ludwig 3 (que significa un grado moderado a severo de alopecia, ya que los grados van del 1 al 4), Ofelia peina su cabello blanco prolijamente hacia atrás, de modo que el raleamiento pasa casi inadvertido (por lo menos para mí). Y entonces hablamos de las diferentes perspectivas que tenemos las personas para mirar un problema (o un asunto) y de que así como yo había llamado ya tres veces al personal de mantenimiento para que reparase la humedad de la pared del consultorio que ella no había advertido, me parecía que la mayoría de las personas que interactuaban con ella no se daban cuenta de su alopecia, pero que igualmente eso no definía la jerarquía de un problema, porque para mí la humedad de la pared era importante y para ella su alopecia también. Ofelia agradeció mucho la consulta y me dijo que no iba a tomar el finasteride y que iba a usar solamente el minoxidil. Un aspecto que me gustaría discutir aquí está relacionado con el conocimiento técnico que se puso en juego en esta consulta y que suele ponerse en juego en muchas consultas del médico de familia. Si Ofelia hubiera venido para conocer mi opinión acerca de un medicamento indicado por un oftalmólogo para una maculopatía, todo habría sido diferente: no sé casi nada de esa enfermedad, y entonces tendría que haberle dicho que iba a estudiar el tema y que volviera otro día, o sencillamente que no la podía ayudar porque no sabía nada de ese remedio y casi nada de la maculopatía. Por el contrario, los temas dermatológicos siempre me gustaron y he intentado mantenerme al día con la literatura, con lo cual, me sentí cómodo con las opiniones que le di en la consulta. En realidad, la opinión general que tenía acerca del tratamiento de la alopecia androgenética en la mujer era que los tratamientos que ofrece la medicina actual son bastante pobres. Sin embargo, mientras hablaba con ella me di cuenta de que hacía por lo menos tres años que no revisaba el tema y me dieron ganas de leer un poco. Los párrafos que siguen expresan lo que habitualmente los médicos buscamos en la literatura médica: la información técnica despojada de la experiencia con un paciente en particular; pero mi objetivo es experimentar y evaluar qué ocurre con un texto cuando esta información aparece, pero también forma parte de un material médico literario en el cual los conceptos habitualmente considerados como técnicos se funden con el devenir de una consulta puntual de un paciente y con las elucubraciones de un médico en particular acerca de esa consulta y de otros temas de su interés. Intentaré ahora producir un material técnico utilizando como fuente el UpToDate (un sitio en Internet publicado en inglés, que considero bastante bueno, aunque a veces no llega a convencerme, donde se resume la literatura médica preferentemente basada en la evidencia científica), con la idea de que pueda funcionar como una revisión práctica del tema, tanto para mí como para un lector ocasional.

El patrón femenino de pérdida del cabello (PFPC), antes conocido como alopecia androgenética en la mujer, es una alopecia no cicatrizal, bastante frecuente en las mujeres adultas, caracterizada por la pérdida insidiosa y progresiva del pelo y que afecta visiblemente su densidad. En la mayoría de los casos, la afección compromete en forma difusa la corona de la cabeza y en algunos casos el compromiso es sobre todo frontal, observándose un patrón en forma de "arbolito de Navidad" cuando la mujer se hace la raya al medio. La línea frontal del pelo usualmente está preservada, a diferencia de lo que ocurre con los hombres (que tienen "entradas"). EI PFPC puede ocurrir a cualquier edad después de la pubertad, pero es mucho más común en la postmenopausia (su prevalencia alcanza el 30\% entre los 70 y los 90 años). Desde el punto de vista fisiopatológico se produce una miniaturización progresiva de los folículos pilosos que determina que esos pelos sean más finos, más cortos y vivan menos tiempo. La causa del PFPC se desconoce y aunque en los hombres la genética y la influencia de los andrógenos tienen una relevancia causal establecida, en las mujeres ambas causas son mucho menos claras y están en franca discusión, motivo por el cual la alopecia 
más frecuente en las mujeres dejó de denominarse androgenética y actualmente se llama patrón femenino de pérdida del cabello (PFPC). La escala de Ludwig es la más frecuentemente utilizada para determinar el grado de severidad del cuadro (va de 1 a 4). La afección ocasiona mucha angustia, malestar y tristeza en la mayoría de las mujeres, disminuyendo la calidad de vida en ocasiones en forma importante. Los médicos que son consultados por estas pacientes deberían tener en cuenta que habitualmente la evaluación que ellos hacen de la severidad del cuadro casi siempre le otorga menor importancia que la percibida por la persona que pide ayuda profesional. El diagnóstico del PFPC es clínico y no es necesario solicitar estudios de laboratorio a menos que se sospeche otra entidad. (Recomendamos buscar en Internet imágenes con el término "female pattern hair loss Ludwig 1, 2, 3 y 4" para mirar varios casos). Es importante preguntar cuándo comenzó la pérdida, a qué ritmo y si hay historia familiar de alopecia, es útil evaluar si existen signos de virilización (hirsutismo, voz gruesa, agrandamiento del clítoris) y si el paciente utiliza fármacos, incluyendo hormonas y suplementos nutricionales. El examen físico del cuero cabelludo y el pelo muestra el patrón característico. Pueden tomarse algunos pelos de la región afectada (corona o área frontal), ponerlos sobre una hoja blanca de papel y comparar su grosor (finos) con el de los pelos tomados de la nuca (gruesos). La presencia de cicatrices, inflamación o escamas debe hacer pensar en otro diagnóstico. El pull test (tomar un pequeño mechón de pelo y tirar) usualmente es normal, a diferencia de lo que ocurre en el efluvio telógeno y en la alopecia areata universal. Están descriptos otros tests diagnósticos, tales como la dermatoscopía y la biopsia del cuero cabelludo, que solamente son necesarios en casos muy raros (tal vez el más relevante es cuando es preciso diferenciar el PFCP de la alopecia areata universal). El tricograma es un test que se utilizaba antes, pero cayó en desuso, y el fototricograma solamente se utiliza en las clínicas especializadas y en estudios de investigación. Los análisis de laboratorio, como ya dijimos, no son necesarios, y solamente tienen sentido si la mujer presenta signos de hiperandrogenismo (hirsutismo, irre'gularidades menstruales, acné moderado, acantosis nigricans o galactorrea), en cuyo caso se debería realizar el dosaje de testosterona y de sulfato de dehidroepiandrosterona, que son normales en el PFPC. Los diagnósticos diferenciales que es preciso tener en cuenta son: el efluvio telógeno (ocurre algunos meses después de una enfermedad grave, de un cuadro de estrés importante, del parto, del uso de algunos remedios o tras una notoria pérdida de peso, y se manifiesta mediante la pérdida aguda o subaguda de cabello en forma difusa, que luego repuebla espontáneamente, no requiriendo tratamiento) y la alopecia areata universal o difusa (es un cuadro muy raro, en el que se pierde casi todo el cabello y para el que casi no hay tratamiento).

En cuanto al tratamiento del PFPC, el minoxidil tópico debe considerarse la primera línea terapéutica, tanto por la evidencia científica acerca de su eficacia como por su seguridad. No se conoce su mecanismo de acción. Se recomienda usarlo dos veces por día, a una concentración del 5\% (aunque, desde el punto de vista estricto, en las mujeres solamente está aprobada la concentración del $2 \%$ ). El fármaco se compra como una loción (existe un preparado en forma de espuma que no se consigue en la Argentina) que se aplica sobre el cuero cabelludo (y no sobre el pelo) del área afectada, masajeando suavemente. Es importante aplicarla por lo menos dos horas antes de irse a dormir para que se seque bien y no se extienda a otras partes del cuerpo durante el sueño. Los efectos adversos son poco frecuentes e incluyen: prurito del cuero cabelludo, irritación e hipertricosis facial (que desaparece al cabo de cuatro meses de suspender su aplicación). La evaluación de la respuesta terapéutica debe hacerse recién a los cuatro meses, aunque para decir que el minoxidil ha sido ineficaz lo ideal es usarlo al menos durante un año. Es habitual que durante los dos primeros meses haya una mayor caída del cabello, situación que es preciso advertirle a la paciente para que no abandone el tratamiento.

La segunda línea terapéutica está representada por drogas de uso sistémico que inhiben la producción o la acción de los andrógenos. Todas están contraindicadas en el embarazo debido a que pueden feminizar al feto masculino. Contamos con datos bastante pobres en relación con su eficacia en las mujeres ya que no existen estudios aleatorizados bien realizados. Están indicadas cuando la paciente no mejora con minoxidil o tiene hiperandrogenismo y se recomienda probarlas sin suspender el uso del minoxidil. En general, la literatura anglosajona propone comenzar con espironolactona, un antagonista de la aldosterona que bloquea los receptores androgénicos e inhibe su síntesis, y que puede brindar cierta mejoría clínica en el $44 \%$ de las pacientes. La dosis utilizada es de $200 \mathrm{mg}$ por día (se recomienda comenzar con $50 \mathrm{mg}$ y aumentar $50 \mathrm{mg}$ por mes hasta llegar a 200 $\mathrm{mg}$ ). Para determinar su eficacia debe usarse por lo menos seis meses. Los efectos adversos que pueden presentarse son: cefalea, irregularidades menstruales, cansancio, disminución de la libido e hiperkalemia. El finasteride es un inhibidor de la 5-alfareductasa, enzima que transforma la testosterona en dihidrotestosterona. Esta droga representa la primera línea de tratamiento de la alopecia androgenética en el hombre y esto se debe a que en su fisiopatología la dihidrotestosterona actúa en forma negativa sobre los folículos pilosos de las áreas frontales y del vértex. Sin embargo, este efecto no parece ocurrir en las mujeres. Pese a que, como hemos mencionado, no hay estudios serios que hayan demostrado su eficacia para tratar el PFPC, en la práctica el finasteride se utiliza frecuentemente en las mujeres, a una dosis de 1 a 2,5 mg por día. Nuevamente, aquí también se prueba durante unos cuatro a seis meses y se evalúa la respuesta. Generalmente esta droga es muy bien tolerada por las mujeres (en los hombres están descriptos muy raramente disminución de la libido y dolor o hinchazón mamaria, pero es mayormente muy bien tolerado). Existe otro inhibidor de la 5-alfa-reductasa, el dutasteride, con el que se está experimentando para el tratamiento del PFPC. El acetato de ciproterona es una droga utilizada mayormente para el tratamiento del acné debido a hiperandrogenismo y que ha mostrado algunos buenos resultados para hacer crecer el pelo en el PFPC. En las mujeres premenopáusicas se indica como un anticonceptivo que ya viene preparado en forma conjunta con etinilestradiol ( 10 a $35 \mu \mathrm{g}$ de esta droga durante 21 días y $50 \mathrm{mg}$ de acetato de ciproterona los días 1 a 10 del ciclo). En las mujeres postmenopáusicas puede usarse $50 \mathrm{mg}$ de ciproterona todos los días. Los efectos adversos potenciales son: irregularidades menstruales, aumento de peso, mastalgia, disminución de la libido, depresión y náuseas. La flutamida es otro antiandrógeno que se utiliza muy raramente para tratar el PFPC, aunque un ensayo clínico bien realizado mostró una mejoría en el $28 \%$ de las pacientes. Los efectos adversos incluyen disminución de la libido, molestias gastrointestinales y alteraciones del hepatograma, siendo la insuficiencia hepática un efecto adverso muy raro, pero que limita su uso. La dosis recomendada es de $250 \mathrm{mg}$ por día.

El trasplante capilar es una técnica microquirúrgica utilizada sobre todo en la alopecia androgenética en los hombres y que ha mostrado algunos resultados estéticamente aceptables en el PFPC. Según algunos autores, los médicos deberían ofrecer esta opción más frecuentemente a las mujeres, debido a que la eficacia de los demás tratamientos para que la paciente se vea mejor es muy pobre, sin embargo, debido a que es un procedimiento que usualmente no está cubierto por los sistemas médicos, no contamos con literatura científica de buena calidad para que pueda ser 
una recomendación validada.

Otros tratamientos que podrían ser de utilidad son: el láser y las inyecciones locales con análogos de las prostaglandinas. La utilidad de la mesoterapia (masajes localizados), así como el uso de suplementos de hierro, vitaminas, biotina, ginseng, aminoácidos, cafeína, etc. es incierto.

El pronóstico del PFPC generalmente no es bueno con las herramientas terapéuticas con las que contamos actualmente. La respuesta a los tratamientos mencionados es variable, pudiendo no constatarse ningún efecto, la detención de la caída, o bien un grado variable (generalmente bajo) de recrecimiento del pelo en las áreas afectadas. Habitualmente la condición progresa, aunque nunca lleva a la mujer a la calvicie, como ocurre en muchos hombres con alopecia androgenética. La recomendación actual es comenzar el tratamiento con minoxidil (y eventualmente con otra droga sistémica antiandrogénica en forma concomitante) en los estadios tempranos y, si la respuesta es buena, continuarlo en forma indefinida. Debido a que las mujeres que consultan suelen estar muy preocupadas por su problema y desean hacer algo, es muy importante que el médico describa las opciones terapéuticas, que aclare que recién puede decirse si un tratamiento ha sido eficaz al cabo de por lo menos cuatro meses de uso y que si la respuesta ha sido satisfactoria este debe continuarse en forma indefinida.

En resumen: cuando una mujer, sobre todo postmenopáusica, consulta porque tiene poco pelo, hay que pensar que el PFPC es la causa más frecuente y que ese problema está alterando la calidad de vida de la paciente. El diagnóstico es clínico y se realiza mediante el interrogatorio y el examen físico. Si la mujer desea tratamiento es importante que el médico le advierta que la respuesta generalmente es muy pobre, pero que puede servir para evitar una mayor caída. La droga de elección es el minoxidil local al 5\%, en dos aplicaciones diarias. Idealmente habría que esperar un año para decidir si el efecto ha sido beneficioso. Si la respuesta es pobre o mala puede intentarse con una droga de segunda línea (básicamente espironolactona o finasteride), que debería indicarse sin alentar grandes expectativas. El trasplante capilar es una opción a tener en cuenta, pero es muy caro.

He aquí la información técnica actualizada a abril de 2015 que, según el uptodate, es preciso tener a la mano para poder atender una paciente que nos consulta por un patrón femenino de pérdida del cabello (PFPC). Cabe destacar que la mayoría de las revisiones que encontramos en la literatura médica incluyen los aspectos desarrollados aquí (definición, epidemiología, fisiopatología, clínica, diagnóstico, tratamiento y pronóstico) pero no suelen contarnos qué le ocurre al médico y a la paciente en la práctica, qué dificultades tienen, etc. A este accionar práctico nosotros lo llamamos manejo e intentamos desarrollarlo siempre que podemos en los textos que producimos (cuando digo nosotros me refiero a la literatura médica que venimos produciendo desde 1997 en el Servicio de Medicina Familiar y Comunitaria, tanto en PROFAM - nuestro Programa de Educación Continua- como en la revista EVIDENCIA y en los libros y revisiones que elaboramos). El manejo es, entonces, un concepto que incluye la tarea de diagnosticar y tratar, pero que está más allá de estos conceptos y que implica una postura, una conducta habitual, una práctica. Existe invariablemente una brecha entre la literatura médica habitual y el manejo. Me pregunto en qué medida el texto que acabo de producir provee herramientas reales para manejar una paciente que consulta por un PFPC.

Me he esforzado durante muchos años para producir textos que intenten minimizar lo más posible dicha brecha, pero soy consciente de que a los médicos nos cuesta atrevernos a manejar pacientes solamente a partir de la lectura de un texto y nos sentimos más cómodos para hacerlo cuando hemos visto a otros profesionales manejando a sus pacientes o cuando podemos contar al menos con un colega que nos refiera cómo maneja (cómo encara, qué hace) un determinado problema, hasta que ganamos experiencia y nos resolvemos a manejar solos. Ahora bien, debemos asumir que los médicos de familia/generalistas, pediatras y clínicos estamos en serias dificultades para manejar entidades que el término medio del ambiente médico y de los pacientes considera que son de resorte del especialista. Como pudimos ver recién, las dificultades técnicas relacionadas con la obtención de conocimiento actualizado (saber qué dice la literatura) son relativamente fáciles de subsanar recurriendo a la literatura actualizada y de calidad, y aunque esos textos muchas veces no son fáciles de encontrar para los médicos hispanohablantes que no acceden a la producción anglosajona, me atrevo a afirmar que todo médico hispanohablante que no lee en inglés puede, si realmente se toma el tiempo para hacerlo, encontrar literatura en español de una calidad y actualidad razonables. Pero los principales problemas que tenemos los médicos de familia relacionados con el manejo práctico de este tipo de entidades no están relacionados con el acceso al conocimiento técnico literario sino que son políticos: por un lado, los pacientes/clientes suelen consultar directamente al dermatólogo por temas relacionados con la alopecia y, por el otro, los generalistas solemos no sentirnos capacitados para manejar a estos pacientes (incluso cuando poseemos conocimientos suficientes acerca del tema). En síntesis: van cristalizándose determinados problemas de salud que se convierten en áreas cerradas, de manejo exclusivo del especialista. Soy médico de familia y creo profundamente (estoy plenamente convencido) en la belleza de nuestra práctica, pero desde una perspectiva abierta (es decir, llegando a la práctica desde el gusto del paciente y del médico por estar ahí, y no desde la imposición del sistema). En este sentido, quiero dejar asentado que de ningún modo considero que la práctica del especialista o la del médico de familia sean taxativamente buenas o malas. El paciente tiene derecho a recibir la atención y el tratamiento de mejor calidad posible, y es muy difícil, en algunos casos, determinar quién es el médico más adecuado para proveerlo. Lo que sí queda claro es que si los médicos de familia queremos manejar a nuestros pacientes con alopecia androgenética debemos estar relativamente actualizados en cuanto a la bibliografía seria (u oficial) de calidad, más allá de que podamos emitir juicios críticos con relación a ella. Un hombre de 33 años de una ciudad del interior del país me vino a ver a principios de mes para conocer mi opinión acerca del uso del finasteride para su alopecia androgenética. Me contó que él quería usarlo porque un amigo lo estaba utilizando con buenos resultados, pero que un médico de familia de su ciudad le advirtió que no lo hiciera porque la droga causaba disminución de la libido, disfunción eréctil y problemas eyaculatorios. Ese médico de familia no posee, a mi juicio, los conocimientos técnicos necesarios para manejar a un paciente que lo consulta por alopecia androgenética y habría sido preferible que se abstuviera de contestar esa pregunta y que derivara al paciente a un colega que maneje adecuadamente el tema (sea este generalista o especialista). Cabe mencionar que el finasteride, utilizado a dosis de $1 \mathrm{mg}$ por día, es la droga de elección para el tratamiento de la alopecia androgenética en el hombre. Se trata de una droga eficaz, tanto para disminuir la caída como para lograr cierta repoblación del pelo. El tratamiento suele ser muy bien tolerado y la mayoría de los usuarios no describen efectos adversos. Muy pocos pacientes refieren disminución de la libido, disfunción eréctil y problemas eyaculatorios, y estos efectos adversos son reversibles si se discontinua el uso. Ahora bien, veamos la otra cara de la moneda. Hace unos días un amigo de 
36 años me contó que había visitado a una dermatóloga por su alopecia androgenética incipiente, una “...capa", pero medio comerciante...", me dijo, y me contó que se trata de una médica de planta de un reconocido Servicio de Dermatología de un Hospital Público de la Ciudad. Mi amigo tiene una Obra Social a la que considera de baja calidad y por eso optó por pagar una consulta privada con esta "capa", cuyos honorarios fueron bastante elevados.

La dermatóloga le indicó $1 \mathrm{mg}$ de finasteride por día, una loción de minoxidil al $5 \%$ en un preparado magistral, un comprimido de biotina (una vitamina) por día y le aplicó un producto (él no sabe qué es) en el cuero cabelludo, citándolo cada quince días durante dos meses para repetir esas aplicaciones. También le pidió un análisis de sangre. La segunda vez que la visitó, al cabo de quince días, volvió a aplicarle el producto $\mathrm{y}$, al revisar sus análisis de sangre, marcó con resaltador amarillo algunos resultados que estaban alterados (según ella). Le comentó que estaba al borde de la anemia y que eso le preocupaba, le dio comprimidos de hierro y le dijo que los valores de las hormonas tiroideas estaban alterados, que seguramente tenía un problema tiroideo y que tenía que ver a un endocrinólogo. Fue ahí cuando mi amigo me pidió ayuda y me preguntó si podía mostrarme los análisis ya que estaba preocupado por lo que le había dicho esta dermatóloga. Lo primero que le pregunté fue cómo le caía esta médica y él me respondió que había ido a verla por recomendación de un amigo al que le había mejorado mucho la calvicie con el tratamiento que le había dado, pero que a él no le había caído muy bien y que le parecía muy comerciante (sobre todo porque le había dicho que comprara la receta magistral del minoxidil solamente en una farmacia de su confianza), pero que parecía saber mucho y tenía muchos diplomas en el consultorio. Generalmente trato de evitar opinar acerca de otros colegas y de mirar estudios de allegados que no son mis pacientes o de darles mi opinión acerca de conductas tomadas por otros médicos porque considero que este tipo de intervenciones suelen atentar contra la relación médico paciente, pero en este caso decidí actuar. Revisé los análisis de mi amigo: tenía la T3 en el límite inferior, con una TSH normal, y una hemoglobina también normal, en el límite inferior (estos eran los resultados marcados con resaltador amarillo). Le dije que sus valores de laboratorio eran normales, que estaba sano y que no era necesario consultar con un endocrinólogo ni tomar hierro. Él se ofuscó con la dermatóloga y me dijo que esa semana tenía que volver a verla para la tercera aplicación y que iba a decirle que estaba molesto porque lo había asustado sin sentido. Yo le dije que no valía la pena hacer eso, que no perdiera el tiempo, que dejara de ver a esa médica y que siguiera tomando el finasteride y usando el minoxidil que era lo único que estaba demostrado que servía. Mi amigo me agradeció, pero se quedó sin médica. Volviendo a nuestras elucubraciones acerca del manejo, podríamos decir que esta dermatóloga, aunque sea una experta en su área, no tuvo la pericia adecuada para manejar a un paciente sano que la visitó por alopecia androgenética. No quiero entrar aquí en discusiones técnicas acerca de la utilidad de la biotina (el uptodate dice que su eficacia es incierta) y las inyecciones en el cuero cabelludo (no sé qué le aplicaba) que le había indicado esta dermatóloga a mi amigo ya que valoro positivamente las prácticas empíricas que no tienen un correlato científico (basado en la evidencia) que realiza cada médico sobre la base de sus creencias, siempre que dichas prácticas no dañen expresamente al paciente y no se realicen con un fin netamente comercial. En este sentido, debemos reconocer que una gran parte de todo los que hacemos a diario los médicos (oficiales) es una práctica empírica personal (un arte) que no está basada en la evidencia científica (y cuando digo hacemos no me refiero solamente a los tratamientos que instauramos, sino a todo lo que dec- imos, a cómo miramos, cómo hablamos, etc.). Sin embargo, más allá de estas consideraciones, tomo una postura (¿política?) y considero que la dermatóloga que atendió a mi amigo no realizó un manejo adecuado (no le proveyó cuidados médicos adecuados) no precisamente porque le indicó la biotina y las inyecciones, ni porque le solicitó un estudio complementario cuando no era preciso hacerlo ya que el diagnóstico de la alopecia androgenética es clínico, sino porque, al no saber interpretar los resultados de dichos análisis en forma adecuada, asustó y medicalizó a su paciente sin sentido. Vemos, entonces, que el tema de los cuidados médicos adecuados o del manejo adecuado (o suficientemente bueno) de los pacientes por parte de los médicos es demasiado complejo como para restringirlo a si debe estar provisto por los generalistas o los especialistas.

Para seguir avanzando por este camino que aparentemente se ha alejado de la mañana luminosa del día de hoy en la que comencé a escribir este texto, propongo que intentemos replantearnos el uso de los términos manejo y cuidados médicos. Mi propuesta se basa en que si bien manejo es una palabra muy útil para describir cómo hacemos en medicina (la cocina), últimamente me está resultando un poco pesada desde el punto de vista epistemológico. Esto es así porque manejar denota un cierto control (o manipulación) del paciente por parte del médico, y este control se contrapone con los conceptos modernos que venimos trabajando en estos últimos años en relación con la importancia de evitar el sobrediagnóstico, la sobremedicalización, el temor y la coacción y favorecer la toma de decisiones compartidas y la contención. Ahora bien, aquí alguien podría aducir que no es necesario replantearse el uso de la palabra manejo y que con solo agregarle el adjetivo adecuado (o suficientemente bueno) incluimos estos nuevos conceptos, pero manejar un paciente sigue teniendo una connotación que ya no me gusta tanto. En cuanto a cuidados médicos, estas dos palabras juntas se trivializaron demasiado y ya no me siven para referirme a los cuidados tal como los entiendo actualmente. Sobre la base de este problema terminológico (o tal vez sobre ninguna base, pero a partir de un nuevo gusto o una nueva creencia), quisiera introducir aquí un término que me está resultando cada día más útil y más bello para referirme al cuidado médico y que descubrí el año pasado leyendo el libro Ser y Tiempo, del filósofo alemán Martin Heidegger'. Se trata del término curar de, que corresponde a la traducción del verbo alemán sorgen, un verbo que no tiene nada que ver con sanar sino que significa hacerse cargo de, tener que ver con, ocuparse de, cuidar de, preocuparse por, interesarse por. (En el español actual las únicas circunstancia que conozco en la que se utiliza el verbo curar con esta acepción es cuando una persona cura de una exposición de arte plástico y, por lo tanto, es su curador; o bien cuando se designa a alguien para hacerse cargo de alguna persona que fue declarada "incapaz" por la justicia, lo que se denomina "curatella"). Me gusta pensar que los médicos en ocasiones curamos de personas (pacientes, familias, etc.), así como en ocasiones curamos de diferentes problemas de salud, de la literatura médica, del sistema de atención médica y, ¿por qué no?, de la salud en general, sin que eso signifique que exista, necesariamente, una sanación o una cura. Me entusiasmo y me animo a enunciar que curar de implica empuñar el cuidado apartándose del mandato del deber médico y abandonando la encrucijada metafísica del dualismo que nos obliga a elegir entre dos opciones: el bien y el mal, los sanos y los enfermos, la enfermedad orgánica y funcional, los problemas de causa psíquica y somática, etc. El acto de curar de está más relacionado con el instante que con el tiempo cronológico, sobreviene sin coacción y se vincula

** En el lunfardo actual (argot del habla de los argentino) se denomina "capo o capa" al jefe, dueño o propietario de una empresa; a quien tiene gente bajo su mando y a quien lo resuelve todo fácilmente. Disponible en: http://neolunfardo.blogspot.com.ar/ 
estrechamente con el intersticio porque no se deja asir. Curar de no es un acto sino más bien un acontecimiento y necesita un intercambio y un entusiasmo. El médico cura de quien puede o de quien quiere, pero no es una circunstancia que él pueda elegir o determinar previamente. Es imposible exigirle a un médico que cure de un paciente determinado ya que se trata de un proceso que ocurre o no ocurre, que puede aparecer o no, y luego irse y volver a aparecer, o no emerger nunca más. Vemos, entonces, que curar de no depende de la voluntad del médico o del paciente; se trata de un acontecimiento que sucede o no sucede. Por lo tanto, no hay forma de introducir en el curar de los conceptos de justicia e igualdad. Por ejemplo, esta mañana, después de atender a Ofelia (de quien creo curar o al menos haber curado de hoy) me consultó un hombre de 53 años, a quien ya vi dos o tres veces, que tiene diabetes y es obeso, para pedirme que le haga unos análisis para ver "cómo estaba todo". Cuando le pregunté si estaba haciendo actividad física, si estaba siguiendo un plan alimentario y si estaba tomando la medicación, el hombre me dijo que como están las cosas no tiene tiempo para ocuparse de él porque está todo el día metido en su negocio de ropa en el barrio de Once. Yo lo revisé, le pedí los análisis que él quería, pero no pude (¿quise?), en esa consulta, curar de él (al menos como me gusta hacerlo con un paciente al que me entusiasma ayudar). Sin embargo, le dije que si alguna vez se hacía de tiempo para ocuparse de él volviera a verme, y me agradeció. Tal vez curé de él de ese modo, no lo sé, pero lo cierto es que esta mañana a mí no me sobrevino el acontecimiento de curar de este paciente. Aquí muchos colegas podrían argüir que no he sido justo con este paciente ya que no hice el suficiente esfuerzo por ayudarlo a modificar sus hábitos e insistir con la toma de la medicación, mientras que me tomé el tiempo para curar de una señora de 82 años que me consultó para conocer mi opinión acerca de la toma de una droga para su alopecia. Según estos colegas, mi accionar de esta mañana fue injusto ya que no quise/pude curar de un paciente diabético que necesita mis servicios y cuya salud corre más peligro que la de Ofelia. No tengo una respuesta acabada a esta crítica, pero lo único que puedo decir aquí es que curar de no puede entenderse como un esfuerzo ni como una voluntad sino como un acontecimiento, que sobreviene o no. Por eso, curar de se aleja indefectiblemente de los conceptos de manejo y de cuidados médicos. Podríamos decir que curar de está mucho más cerca del arte que de la ciencia, y todo arte tiene algo de indómito e irredento.

Esta es la primera vez que escribo este nuevo verbo hermoso que le robo a Heidegger, y no sé muy bien por qué, pero tengo la sensación de que pensar a la medicina como la práctica de un sorgen, de un curar de, tal vez represente un cambio en la forma en la que pensamos nuestra práctica. Me entusiasma la idea de convocar a mis colegas a crear la medicina del sorgen, una medicina que deje de lado la compasión, el deber, la moral, la causalidad banal, la culpa, el historicismo, el nihilismo, la dualidad metafísica, el bien y el mal, la búsqueda imperiosa de la verdad, la sobrevaloración de la razón y el conocimiento, la separación entre alma y cuerpo y entre enfermedad orgánica y psíquica para transformarse en una medicina que valore la incertidumbre y que prepare el campo para que acontezca el curar de, el tener que ver con y el interesarse por como valores en sí mismos y no como valores que sirvan para algo o que tengan un fin o una causa. La medicina del sorgen no pretende transformar la realidad sino disfrutar del instante y de la incertidumbre de la vida. Curar de (a diferencia de manejar adecuadamente o proveer cuidados médicos adecuados) no obedece a la voluntad, ni al mandato, ni a ninguna orden (no se pueden escribir guías de práctica clínica para curar de), y si bien sobreviene (acontece) en forma intempestiva, tanto los médicos como los pacientes podemos prepararnos o no para que este acontec- imiento acontezca. Este prepararnos está más vinculado con el interés y el entusiasmo que con la obligación y el deber ser. Curar de es una práctica alegre que no se deja aprehender por la técnica, pero que disfruta de la técnica y utiliza sus ventajas, entrando y saliendo de ella como le plazca.

Volvamos ahora a Ofelia. Todo esto comenzó a partir de la consulta que tuvo esta mañana conmigo. Ahora podemos decir que lo que ocurrió hoy con ella ha sido un acontecimiento en el que hubo un sorgen, un curar de, un tener que ver con. Por la tarde, cuando terminé de atender los doce pacientes que vi en el consultorio, comencé a escribir este texto, leí el uptodate, aprendí que el término alopecia androgenética en las mujeres hoy se denomina PFPC y tuve ganas de traducir y resumir el tema para mí y para mis eventuales lectores. Me entusiasmé, seguí escribiendo y fue entonces cuando se me apareció (me aconteció) el término curar de. $\mathrm{Y}$ hay ahí una linda combinación entre curar de y pensar en, ya que este texto solamente es posible porque yo pensé en Ofelia, pero el sorgen, como el instante y el intersticio, es indómito, y a esta altura Ofelia dejó de ser la protagonista exclusiva de esta red de cuidados que fui armando porque ahora también aparecieron los lectores. $Y$ es entonces (ahora) cuando, pensando en ellos (y también en mí, es decir, en nosotros), preparándome para un posible curar de, me acontece el entusiasmo por curar del lector que está leyendo este texto porque desea manejar adecuadamente a sus pacientes con PFPC (vimos que sería imposible escribir un texto para curar de ya que se trata de algo que acontece o no y que, por lo tanto, tenemos que contentarnos con escribir textos para manejar adecuadamente o para proveer cuidados médicos adecuados). $Y$ entonces, pensando en todo esto, tengo que reconocer, como ya dije antes, que las revisiones bibliográficas solamente representan un punto de partida para estar preparado para curar de (fíjense que ya no digo para manejar) los pacientes, y aunque sé que es muy difícil que un médico se atreva a manejar (aquí sí) a un paciente solamente a partir de la lectura de un texto, me doy cuenta de que preparar el campo para eventualmente curar del lector que sigue leyendo este texto principalmente porque desea información acerca del PFPC implica avanzar un poco más, y tengo ganas y tiempo para hacerlo.

Aquí me empantano un poco. Busco papers en Internet sobre el PFPC que hayan sido publicados entre 2015 y 2012 en revistas médicas que me parezcan relativamente serias. Leo el abstract de un artículo cuyo título parece reconocer como positivo el uso tópico de análogos de las prostaglandinas F2 alfa (bimatoprost y latanoprost) para el crecimiento del pelo. Se me ocurre que tal vez sea esto lo que le está aplicando la "capa" a mi amigo en su cuero cabelludo. Me entusiasmo con el tema (cito aquí el artículo ya que no creo que valga la pena que aparezca al final de este ensayo formando parte de la "Bibliografía": Promising alternative clinical uses of prostaglandin F2a analogs: Beyond the eyelashes. Choi, Young M. et al. Journal of the American Academy of Dermatology, Volume 72, April 2015, Issue 4, 712 - 716) y me imagino a la "capa" tomándose el taxi desde su departamento en un barrio lindo de Buenos Aires, podría ser Recoleta o Belgrano, hasta el aeropuerto de Ezeiza, en una mañana helada de junio de 2011, para asistir al Congreso Mundial de Dermatología en Seúl. Me la imagino sentada junto a los compañeros de su Hospital en la conferencia en la que Young $\mathrm{M}$ Choi, a quien imagino como un médico norteamericano de origen coreano (lo googleé y comprobé que es un varón), exponiendo sus investigaciones acerca del efecto positivo que tienen las prostaglandinas F2 alfa sobre el crecimiento del pelo, un efecto que se encontró casualmente, como muchos de los efectos interesantes en la ciencia, al comprobar que a las personas que tienen glaucoma y usan estas drogas en forma de gotas oftálmicas les crecen más las pestañas -de ahí el hermoso 
subtítulo del paper: beyond the eyelashes (más allá de las pestañas)-. Me gustan estas cosas, me gusta la ciencia y la medicina, me gusta el modo como la medicina cree en la ciencia y la ciencia cree en ella, me gusta imaginarme a "la capa" escuchando extasiada al oriental, pero hay allí algo que no me cierra, algo relacionado con Choi. Releo el abstract y me doy cuenta de que en realidad Young $M$ Choi no es un investigador, sino que hizo una revisión bibliográfica sobre los análogos de las prostaglandinas F2 alfa y la publicó (sería algo así como lo que hice yo más arriba con el PFPC, aunque lo mío es menos serio porque yo simplemente adapté y traduje el uptodate). Esta constatación me lleva a pensar que es muy poco probable que Choi haya viajado a Corea en 2011, aunque tal vez tiene familiares allí y aprovechó el congreso para viajar y visitarlos. Entonces me pregunto: ¿A qué conferencia pudo haber ido "la capa" en Seúl para entusiasmarse tanto con este nuevo producto? Sigo buscando y encuentro finalmente a una investigadora llamada Ulrike Blume-Peytavi (la googleé y es una mujer que vive en Berlín) que publicó, en la misma revista que Choi, pero en mayo de 2012, un ensayo clínico aletorizado placebo control (el sumum de la investigación científica) en el que demuestra que el latanoprost es superior al placebo para hacer crecer el pelo en varones jóvenes con alopecia androgenética. Decido no citar el artículo aquí porque su título es muy largo, pero me fijo en el uptodate y veo que figura en las citas. $Y$ ahora todo cuaja: me imagino a "la capa" escuchando la conferencia de Ulrike en Seúl un jueves por la tarde y charlando el viernes por la mañana con sus colaboradores y colegas en el desayuno del hotel acerca de su interés por este nuevo tratamiento. Me imagino su expectativa y su entusiasmo al comprobar la eficacia de este nuevo tratamiento en su práctica pública y privada en Buenos Aires. $Y$ ahora me la imagino en la oficina de su despacho, ultimando los detalles con un representante de una empresa farmacéutica que produce latanoprost y que va a apoyar financieramente a su grupo para el viaje que están organizando a Vancuver para asistir el Congreso Mundial de Dermatología que tendrá lugar en junio de este año (2015) y de repente me sobreviene una idea que me disgusta: ¿por qué le dije a mi amigo que dejara de aplicarse las inyecciones que le estaba haciendo "la capa"? ¿quién soy yo para desestimar un tratamiento sin conocerlo? Releo lo que yo mismo acabo de escribir hace tan solo algunas horas cuando traduje y adapté el uptodate y leo: "Otros tratamientos que podrían ser de utilidad son el láser y las inyecciones locales con análogos de las prostaglandinas". ¿Y si "la capa" estuviera revolucionando el tratamiento de la calvicie incipiente en los jóvenes varones porteños gracias a que ella es de las pocas dermatólogas en la Argentina que conocen (o que creen en) el efecto beneficioso del latanoprost sobre el folículo piloso hormonosensible y está utilizando la droga con éxito mediante aplicaciones cada quince días en el cuero cabelludo? Desestimé a "la capa" por dos razones: porque mi amigo me dio el pie (me preparó) para hacerlo ("es medio comerciante", me dijo) y porque yo me dedico particularmente (¿intento estar preparado para curar de?) a los temas relacionados con los daños que le ocasiona la medicina a las personas sanas en su afán por diagnosticar y curar (concepto también conocido como "prevención cuaternaria"). Pero mi colega se dedica particularmente a la dermatología, y tal vez sea "una capa" en los suyo. Alguien podría decir que las verdaderas razones por las cuales desestimé a "la capa" no son las que mencioné, sino las siguientes: envidio que viaje a los congresos (es cierto: me encantaría conocer Seúl y volver a Vancuver), que gane mucho dinero y que sea una "capa", pero creo que estas elucubraciones son terreno del psicoanálisis y prefiero no meterme hoy con eso. Pero sí quisiera aprovechar esta instancia para pedirle perdón públicamente a esta colega por haber opinado de balde acerca de su práctica y, más aún, sin conocerla. Tal vez debería haberme dedicado solamente a decirle a mi amigo que sus análisis estaban bien, aunque en realidad lo mejor habría sido que me abstuviera de opinar del todo, porque si lo hacía parcialmente igual iba a desvalorizar una de sus acciones médicas y atentar contra la relación médico paciente que, por mi culpa, se perdió. También debería pedirle perdón a mi amigo porque, como dije más arriba, perdió a la dermatóloga que había elegido libremente, y yo no le ofrecí un médico a cambio. Tal vez deba darle a leer este texto, aunque no creo que lo ayude mucho a esta altura, y me parece que es mejor que las cosas queden así y que solamente el devenir nos diga qué va a pasar de aquí en adelante. Aunque estas elucubraciones me llevan a pensar que tal vez debería encontrar de algún modo a "la capa" y preguntarle qué droga usa ella en el cuero cabelludo de sus pacientes con alopecia androgenética, pero no me atrevería a hacerlo, me parecería muy cínico de mi parte. Ya está. Siempre se aprende algo. $Y$ todo esto que me ha ocurrido me lleva a pensar que si realmente tengo ganas y tiempo de preparar el campo para eventualmente curar del lector que sigue leyendo este texto principalmente porque desea información acerca del PFPC tengo que salir de este embrollo y conectarme con el afuera. $Y$ así como Ofelia y mi amigo necesitaron vincularse conmigo para pedirme ayuda, yo ahora necesito vincularme con alguien de mi confianza que practique algo de esto, que maneje, que esté preparado para curar de (cuando acontece) pacientes como Ofelia. Necesito ver qué está pasando afuera. Le escribo este mail a una amiga dermatóloga: Buen día. Un favorcito grande. ¿Podrías responderme estas preguntas? 1) ¿Cuánto creés (del uno al diez) que puede ayudar la terapéutica dermatológica actual para mejorar la alopecia androgenética en la mujer? y 2) ¿Cuáles son los tratamientos que indicás para esta entidad en los que realmente "creés" y cuál es el puntaje (del uno al diez) de eficacia que le otorgás a cada uno de ellos? Mi amiga me responde: Pregunta 1) $4 / 10$. Pero como en muchas otras afecciones progresivas, los efectos más beneficiosos se ven cuanto antes comienza el tratamiento. Pregunta 2) Aminoterapia: 6/10 (mejora la calidad del pelo), minoxidil al 2 o al 5\%: 6/10 (engrosa el pelo y enlentece la progresión de la enfermedad) y finasteride $2,5 \mathrm{mg}$ (en mujeres que no estén en edad fértil y no tengan antecedentes personales 0 familiares de cáncer de mama): 7/10 (enlentece la progresión de la caída y en estadios iniciales crece pelo nuevo). Encuentro muy interesantes sus respuestas y le agradezco. Vemos que ella utiliza un tratamiento que la literatura que consulté no valora (la aminoterapia, que es el uso de aminoácidos) y que la espironolactona y la flutamida no forman parte de su práctica, pese a que en la bibliografía que busqué ambas drogas cuentan con mayor evidencia a favor que el finasteride, droga que mi amiga sí utiliza y que probablemente represente el manejo habitual del PFPC de los dermatólogos argentinos. También me llama la atención que le dé la misma jerarquía al riesgo de embarazo que al antecedente de cáncer de mama en relación con las precauciones que hay que tomar para indicar finasteride en una mujer. En este caso, el riesgo de cáncer de mama parecería ser una preocupación más de ella que de la dermatóloga que atendió a mi paciente. Busco el prospecto de la marca comercial del finasteride que compró Ofelia y leo: Debe informar inmediatamente a su médico de cualquier cambio en el tejido de la mama, como bultos, dolor, aumento del tejido de la mama o secreción del pezón, ya que éstos pueden ser signos de una enfermedad grave, tal como cáncer de mama. Reviso la literatura académica y compruebo que la relación entre el uso del finasteride y el cáncer de mama está mencionada, pero que no se cuenta con evidencia para determinar una asociación relevante, tanto en los varones como en las mujeres que utilizan la droga. Meterme nuevamente en Internet para buscar información me conduce a cientos de sitios sobre el tema. Navego pasmado por la profusión de información y me angustio un poco cuando imagino a todas las personas que consultan diariamente la red global para ver qué hacer o qué se está haciendo con un determi- 
nado problema que atañe a su cuerpo. Me encuentro con el sitio web www.recuperarelpelo.com que atrae mi atención, y lo recorro. En el apartado quiénes somos, leo: recuperar el pelo está integrado por un grupo de personas que desea compartir contigo sus experiencias y puntos de vista sobre la alopecia. Nuestra única intención es informarte e informarnos. Compartir nuestras experiencias y que tú nos enseñes las tuyas. Creemos que para resolver un problema, lo ideal primero es estar informado. Conocer el problema, estudiarlo y luego poner manos a la obra. El sitio está muy bien hecho y me gusta; no logro identificar quién lo financia ya que en todos los tratamientos están distinguidas sus ventajas y desventajas, y aunque sé que si llegué allí es porque alguien se ha ocupado de eso con estrategias de márketing digital, me parece que podría recomendarlo como un buen sitio sobre el tema de la alopecia, tanto para médicos como para pacientes/clientes. Lo navego e insensiblemente llego a un tratamiento que mencioné en el resumen que hice antes, pero sin describirlo en detalle: el trasplante capilar. Veo que hay dos técnicas quirúrgicas modernas: 1) La FUSS (folicular unit strip surgery), en la que se remueve una tira (strip) de cuero cabelludo del área donante (nuca), de la que se extraen unidades foliculares que luego se implantan en las áreas alopécicas. La técnica deja una pequeña cicatriz que usualmente se cubre por el cabello que la rodea y 2) La FUE (folicular unit extraction), en la que se extraen los folículos del área sana sin hacer un corte, utilizando un aparato que actúa como un sacabocado que contiene una unidad folicular que se implanta en las áreas enfermas. Es mucho más costosa y la ventaja es que no quedan cicatrices. Ambas técnicas son caras, las cirugías insumen bastante tiempo (una o dos sesiones de cuatro a seis horas), son realizadas por cirujanos plásticos y si el resultado es positivo este se sostiene a lo largo del tiempo. También veo que en el sitio se le da mucha más relevancia que en la literatura consultada al uso de pelucas; se describen las diferentes calidades de pelucas que hay en el mercado y se plantea que es una excelente opción para las mujeres (habitualmente desestimada en forma prejuiciosa por los médicos y los pacientes) ya que en ellas, a diferencia de lo que ocurre con los hombres, el trasplante no suele aportar buenos resultados. El tema de las pelucas me angustia un poco y busco más información acerca del trasplante hasta que encuentro varios sitios que lo recomiendan en las mujeres con PFPC. Estas páginas tienen menos prurito para combinar la información científica con la publicidad explícita. Me dejo llevar y me sumerjo en centros de medicina estética y blogs de cirujanos plásticos. Se trata de una medicina que me es ajena y en la cual la publicidad y el márketing se realizan sin subterfugios. Me divierte haber comenzado mi búsqueda por publicaciones oficiales de la medicina académica y encontrarme ahora en una gran tienda en la cual el comercio y el lucro son explícitos. Encabezando la página web de un exitoso y mediático cirujano plástico argentino que realiza microtrasplante capilar leo esta cita de Voltaire (1694 1778): "El arte de la medicina consiste en entretener al paciente mientras la naturaleza cura la enfermedad". Me quedo pensando en si algunos de sus numerosos y famosos clientes habrán leído concienzudamente esa cita y habrán relacionado esa cita con el momento en el que el exitoso médico les dijo que la calvicie nunca mejora sola. Me pregunto si puso esa frase ahí porque le gustó y nada más, si hay una intención más profunda o si se trata de puro cinismo. Me interesa el tema de la relación ambigua de la medicina con el mercado y el consumo. Le escribo otro mail a mi amiga dermatóloga y le pregunto: ¿Sabés algo del trasplante capilar para la alopecia androgenética en las mujeres? y ella me responde: Sí, la técnica se llama FUE, es trasplante pelo por pelo, es engorroso y muy caro, pero los resultados son excelentes. Entonces le pregunto: ¿Por qué no mencionaste el trasplante entre las respuestas en el mail anterior? Y te agrego una pregunta más: asumiendo que el trasplante fuera gratuito y accesible a todas las pacientes con
PFPC, ¿qué puntaje le otorgás en cuanto a su eficacia? Y ella me responde: No mencioné el trasplante porque no se hace en el Hospital y porque es muy caro (se está cobrando entre 6.000 y 12.000 dólares). Le otorgaría un 8/10 de puntuación. Pienso en el mercado y en las tensiones que generan las prácticas en la provisión de los cuidados médicos. ¿Por qué el sistema de salud (Obras Sociales, el Estado, las Prepagas) financia (cubre) costosísimos tratamientos oncológicos que solamente prolongan la vida unos meses en pacientes terminales y no cubren la medicina estética? La respuesta parece sencilla, pero no lo creo tanto. Cada vez me parece más complejo delimitar la medicina útil de la inútil, la medicina "estética" y la medicina "médica". Hay todavía colegas a quienes les molesta que haya médicos que se dediquen a "temas frívolos", como si la detección y el tratamiento de la hipertensión arterial en las personas asintomáticas fuera un tema "importante" y el tratamiento de la alopecia androgenética fuera una frivolidad o un negocio. Estos colegas suelen argüir que la salud es un derecho y que es imprescindible separar a la salud del mercado. Yo también considero que es un derecho, como la vivienda, el trabajo y la alimentación, pero el problema es que estos derechos están dentro del mercado, y la salud del siglo XXI está inexorablemente enclavada en el consumo y el mercado. Me parece que es hora de que aceptemos esta realidad y dejemos de negar la ambigüedad y las tensiones que nos generan día a día, en todos los ámbitos de nuestra práctica, los problemas relacionados con el hecho de que la salud está visceralmente subsumida por el mercado. El tratamiento (el manejo) de la alopecia es un ejemplo muy interesante: Ofelia puede visitar a un dermatólogo o a su médico de familia sin tener que pagar la consulta (está "cubierta") y si compra la medicación indicada para su afección tiene un descuento en la farmacia otorgado por su cobertura; mi amigo decidió pagar la consulta para ver a la "capa" y además pagó la totalidad de la medicación indicada porque esta dermatóloga lo mandó a una farmacia determinada que no hace descuentos, pero todo esto son minucias si uno las compara con el dinero que está en juego en relación con la alopecia. Y este dinero presiona desde distintos ámbitos. Cuando navegaba en Internet buscando información académica descubrí que hay una página en la Wikipedia dedicada exclusivamente a los tratamientos experimentales de la alopecia androgenética. El sitio quiere ser serio, y comienza como la cita de Voltaire, con un mensaje cándido y pío: el campo del tratamiento experimental de la alopecia androgenética es vasto y comprende el uso de tratamientos tópicos y sistémicos con diferente grado de eficacia. Solamente en los Estados Unidos forma parte de una industria multibillonaria. El enorme terreno de la investigación no puede abarcarse en forma apropiada en un solo texto, pero en este artículo se discuten los tratamientos que cuentan con la mayor cantidad de investigación de calidad y revisada por pares. Me pregunto quién financió a los que armaron ese sitio en la Wikipedia y qué significa hoy en día investigación de calidad y revisada por pares. Todos los que nos dedicamos a la medicina sabemos que actualmente la ciencia médica forma parte del mercado y que la mayoría de las investigaciones están financiadas por la industria farmacéutica. $Y$ aunque es probable que los análogos de las prostaglandinas F2 alfa sean eficaces (figuran, por supuesto, en la página de la Wikipedia) todos sabemos que el Congreso Mundial de Dermatología de Seúl en 2011, y el de Vancuver en 2015, y todos los viajes a esos congresos de los profesionales que asisten a ellos, y el $99 \%$ de los congresos médicos que se realizan en el mundo, y gran parte de los viajes que realizan los médicos para estar ahí, son financiados por la industria. $Y$ todo esto sigue siendo una minucia si se lo compara con el dinero que invierte la industria farmacéutica en el financiamiento permanente de investigadores y profesionales, publicidad, lobby, márketing, etc. Pero el tema de la industria farmacéutica y su relación con la práctica médica es interesantísimo para describir el 
riego que representa caer en la encrucijada metafísica del bien y el mal. La industria no es buena ni mala, forma parte, simplemente, de las reglas de juego de la sociedad capitalista y de consumo. Y por eso me resulta mucho más interesante observar todo esto y reflexionar, que enojarme. Me resulta interesante observar cómo pelean esas fuerzas en el mercado y cómo nos llega esa puja a los médicos en la práctica al consultorio. Me pregunto cuánto dinero mueve el microtrasplante capilar en el mundo y qué ocurrirá con él en cuanto a su cobertura en los próximos años. Tal vez siga siendo una práctica exclusivamente privada o tal vez la presión social y del mercado aumenten (como ocurre con gran parte de la tecnología médica) y los financiadores se vean obligados a aceptar que la alopecia es un problema de salud como otros tantos y que el acceso a un trasplante capilar también es un derecho, así como lo son las técnicas de reproducción asistida, la medicación antihipertensiva o la quimioterapia. Y esto ocurre actualmente con gran parte de las afecciones del cuerpo. A muchos médicos de familia nos gustaría atender a nuestros pacientes creyéndonos fuera del mercado, sin entrar en la dinámica del consumo, pero todos sabemos que esto es imposible.

Me detengo nuevamente. Tomo aire y me estremezco un instante porque barrunto que hemos llegado a una instancia crucial. Hemos llegado al mercado y al consumo partiendo del PFPC como viñeta clínica y del curar de como propuesta epistemológica. Podemos hacernos los osos y avanzar dejando de lado el mercado y el consumo (que a los médicos de familia por lo menos nos suele resultar espinoso y, como ya dije, a veces preferiríamos creer que nuestra práctica está por fuera de ellos) o bien incorporarlos como parte de la complejidad y de las preguntas que nos compete formularnos. Prefiero tomar el riesgo de incorporarlos y entonces mi estremecimiento toma cuerpo y aprovecho la sensación de haber llegado a una instancia crucial para formular una pregunta crucial. Y recién ahora, cuando me atrevo a acercarme a esta pregunta, me doy cuenta de que la discusión acerca del mercado y el consumo en relación con la medicina solamente tiene sentido para los médicos de familia que atendemos pacientes en el consultorio si realmente nos sirve para formularnos dicha pregunta. Enuncio, pues, la pregunta que nos corresponde hacernos: ¿Qué significa, para un médico de familia, estar preparado para curar de un paciente, hoy en día, en una sociedad de consumo? Y esa misma pregunta podría pensarse también cambiando al paciente por la literatura médica (curar de la literatura médica) y la comunidad (curar de la comunidad). Es decir, esa misa pregunta podría formularse de este modo: ¿Qué significa, para un médico de familia, estar preparado para curar de la comunidad (en términos de salud pública), hoy en día, en una sociedad de consumo? Y a ambas preguntas uno también podría sacarles el apelativo "de familia" y dejarlas formuladas de un modo más abierto: ¿Qué significa, para un médico, estar preparado para curar de un paciente (o de la literatura médica, o de la salud de la comunidad), hoy en día, en una sociedad de consumo? No creo que la respuesta que intentaré elaborar sea muy diferente con el apelativo "de familia" o sin él, o si se cura de un paciente, de la literatura médica o de la comunidad, pero prefiero ceñirme a la primera pregunta sobre todo para ser fiel a la ontología de este texto, que surgió a partir de una consulta mía (la de un médico de familia) con Ofelia (una paciente) esta mañana luminosa de abril. Quiero advertirle al lector que no creo que pueda contestar la pregunta que nos formulamos en forma taxativa y que el intento de responder ira viniendo de a poco, como el agua que se acerca a la orilla del Río de la Plata en una jornada calma y soleada de invierno. Lo único que tengo claro es que la respuesta no podrá venir (ni quiero que lo haga) desde una perspectiva metafísica, donde abreva la dualidad del bien y del mal, sino desde el amor por la incertidumbre y el respeto por la ambigüedad. Si hay algo que tengo claro en relación con esta pregunta es que mi postura (y me imagino que la de muchos colegas) es visceralmente ambigua. Pero debemos avanzar e intentar darnos una respuesta, aunque sea extensa y ambigua y apele al circunloquio y a los ejemplos. Partiendo de la ambigüedad como un lugar rico en sensaciones para elaborar una respuesta, y dejándome llevar por mis pensamientos sin temerle al circunloquio, lo primero que me viene a la cabeza es la homeopatía, probablemente por su relación particular con el mercado y el consumo. Tengo algunos colegas médicos de familia que la practican y conozco algo de su epistemología. No creo en la epistemología homeopática que plantea que "lo similar cura lo similar", ni en su terapéutica basada en las diluciones, y menos que menos en los globulitos y los preparados que indican. Tampoco me gusta mucho la relación que establecen algunos pacientes con su homeópata (una relación a mi juicio usualmente rayana en la dependencia y la sumisión). Sin embargo, creo en el poder de la práctica homeopática, en la contención y capacidad de cura (o de entretenimiento, citando a Voltaire) que les provee a algunos pacientes y valoro a muchos colegas que trabajan con dedicación con sus pacientes y los ayudan visiblemente. Me gusta observar en qué medida la homeopatía ocupa un espacio en el hueco que deja la medicina oficial al descuidar (o dejar de lado) ciertas necesidades de algunas personas que piden ser cuidadas de un modo más "particular". Los homeópatas practican lo que hoy en día se define como medicina alternativa, término inventado para referirse a toda práctica médica que no pertenece a la medicina oficial (aquella que, supuestamente, practico yo) y mayormente se ejercen por fuera de las coberturas médicas tradicionales (Obras Sociales, prepagas y el Estado). Es interesante observar que la homeopatía se mantiene ajena a la dinámica del progreso tecnológico y que su modelo no se asienta en la estrategia capitalista de incorporar constantemente novedades al mercado sino que, por el contrario, su terapéutica se basa mayormente en la utilización de los mismos compuestos farmacológicos diluidos que cuando se la inventó a fines del siglo XVIII. Sin embargo, esta ajenidad en relación con la dinámica del mercado es aparente ya que la homeopatía forma parte de una dinámica de consumo en la que los profesionales cobran honorarios no reglados (y usualmente elevados) e indican recetas magistrales preparadas en farmacias específicas. Es decir, nos encontramos aquí con una práctica que está insertada en el mercado, pero que tiene una dinámica de consumo diferente a la de la bibliografía y la búsqueda de material que he realizado hasta el momento en relación con el PFPC. Me pregunto, ahora, cómo encararía un homeópata a un paciente que lo consulta por alopecia y, pensando en lo que acabo de escribir acerca de las aguas del Río de la Plata que se acercan a la orilla, es decir, aprovechando que tengo ganas y tiempo de continuar con esta búsqueda, decido escribirle un mail a un amigo homeópata, preguntándole si tiene algo para ofrecerle a una señora de 82 años que consulta por PFPC. Él me responde: Por supuesto. Nosotros no tratamos solamente un síntoma o un signo, sino a la persona integralmente. Se puede hacer un tratamiento de fondo para mejorar su problema. No sé si con lo que le dé va a crecerle más pelo, pero va a sentirse mejor, va a verse mejor ella y va a estar menos preocupada por su pelo. La respuesta de mi colega es tan reveladora que repentinamente me sobreviene una posible respuesta a mi pregunta ¿Qué significa, para un médico (de familia), estar preparado para curar de un paciente (o de la literatura médica, o de la salud de la comunidad), hoy en día, en una sociedad de consumo? (podemos observar que incorporé las demás alternativas utilizando paréntesis ya que mi respuesta es tan sencilla que no me asusta la complejidad de las incorporaciones). $Y$ la respuesta me ha sobrevenido en forma de acontecimiento (sin haberlo buscado con la voluntad, como ocurre siempre con el curar de) y yo estaba preparado para ello. He aquí, entonces, la respuesta a una pregunta que yo considero crucial para nuestra práctica y que 
cuando la formulé pensé que sería sumamente compleja y ahora se me representa sencilla y luminosa: Para un médico de familia (o para todo médico), estar preparado para curar de un paciente (o de la literatura médica, o de la salud de la comunidad), hoy en día, en una sociedad de consumo, significa aceptar que todos nuestros actos (y curar de es uno de ellos), están basados en nuestras creencias.

Me imagino que habré decepcionado a algunos lectores, pero a mí me gusta mucho esta respuesta a mi pregunta. Tenía que llegar de algún modo a las creencias, porque estas representan la base de cómo miramos el mundo, es decir, de nuestra perspectiva, y la medicina, la sociedad de consumo y el curar de no son más que perspectivas. Tenía que llegar a las creencias para ablandar la exigencia sobre el accionar médico y para blanquear que los médicos actuamos sobre la base de nuestras creencias y que estas muchas veces están sobrevaluadas, tanto por nosotros mismos cuanto por la sociedad en general. Asumir (aceptar) que la práctica médica está basada en las creencias de quienes la practican (tanto los médicos, como los pacientes como la sociedad toda) puede parecer una obviedad, pero si filmáramos las discusiones que tenemos los médicos acerca de las diferentes prácticas veríamos que la mayoría de nosotros tenemos muchas dificultades para aceptar las creencias de los demás. $Y$ entonces apelamos a la ciencia como si esta no fuera una creencia más, y lo que yo planteo aquí es que todo esto puede ser más sencillo si nos ablandamos y aceptamos la diversidad de creencias que existen. $Y$ aunque a algunos les parezca una obviedad, considero que aceptar que todos nuestros actos (y curar de es uno de ellos) están basados en nuestras creencias es la forma más compleja ( $y$ moderna), para un médico de familia (o para todo médico), de estar preparado para curar de un paciente (o de la literatura médica, o de la salud de la comunidad), hoy en día, en una sociedad de consumo. No quiero "explicar" esta frase. No sabría hacerlo y, además, no creo en las explicaciones, pero intuyo que el problema con las creencias es similar al problema del Ser. Usamos el verbo ser de un modo tan general que es muy difícil pensar acerca de su origen y su significado. Heidegger dedicó todo un libro, Ser y Tiempo, a desmenuzar el origen y el significado del Ser. Yo comencé a leerlo el año pasado, recién leí menos de la mitad y me resulta muy bello y complejo. Es llamativo cómo una persona ha podido proponerse desmenuzar el Ser del mismo modo que un arquitecto se propone construir un edificio. Seguramente hay excelentes libros escritos acerca del creer y las creencias. Nietzsche, uno de los pocos autores teóricos que he leído, además de Heidegger, se dedicó a desmenuzar las creencias, pero aunque no hayamos leído ningún texto específico todos sabemos que la vida de todas las personas, la literatura universal, la política, la crianza, la religión y, obviamente, la medicina están atravesadas por las creencias. No me siento capacitado para realizar aquí un comentario interesante acerca del origen y el significado de las creencias, pero lo único que me atrevo a decir ahora es que, según mi perspectiva, las creencias forman parte de nuestro cuerpo. Me gusta la frase que acabo de escribir, sobre todo porque la considero muy médica. La googleo colocándola entre comillas y me da mucha alegría que en la computadora aparezca el texto: "No se han encontrado resultados para las creencias forman parte de nuestro cuerpo". Me alegra pensar que mi frase es original (si le saco las comillas aparecen 796,000 resultados, pero eso es otro cantar). Si bien me gusta esto nuevo que acaba de surgir (que las creencias forman parte de nuestro cuerpo) decido que es un tema que dejaré para otro momento; simplemente quisiera decir aquí que considero que esa pertenencia de las creencias al cuerpo no significa rigidez sino, por el contrario, como todo lo que ocurre con nuestro cuerpo, significa posibilidad (o no) de movimiento y de cambio.
Volvamos ahora a la respuesta que acabo de encontrar para mi pregunta, a esta propuesta que hago de aceptar que todos nuestros actos están basados en nuestras creencias y que considero como la forma más compleja (y moderna, y bella, y que más me gusta) de curar de para un médico. Para abrevar en esta complejidad me propongo recorrer de adelante hacia atrás los personajes que han ido apareciendo en este ensayo y reflexionar acerca de sus creencias y de cómo se preparan para curar de en un mundo complejo, subsumido en una sociedad de consumo. El primer personaje es mi amigo homeópata. Él cree en la homeopatía y contesta a mi pregunta desde su creencia. Ahora bien, la respuesta que me dio, si bien es interesante y me sirvió para disparar mi respuesta, no creo que pueda ayudarme para ofrecerle una eventual alternativa terapéutica a Ofelia (o a una paciente con PFPC). Sin embargo, es interesante destacar que en todas estas páginas, hasta el momento en el que habló mi amigo homeópata, ningún "personaje" (y yo tampoco) había propuesto darle algo a Ofelia solamente para que se sienta mejor. Es cierto, mi amigo homeópata asume que si Ofelia consultó a un dermatólogo por su alopecia es porque está angustiada por eso (dato que corrobora la literatura "científica") y así como él le daría algo, yo creo haberla reasegurado con el ejemplo de la pared de mi consultorio, pero no le di ninguna sustancia específica para que ella incorpore o aplique sobre su cuerpo. Evidentemente yo creo en la potencia terapéutica del reaseguro médico con la palabra, pero reconozco que a veces creemos demasiado y soslayamos la importancia del contexto, que muchas veces pide una respuesta desde el consumo (pide un objeto, una técnica, algo más tangible que la palabra). Volviendo a la homeopatía, he mencionado que no creo, pero tampoco me enojo con ella, acepto que puede serle útil a algunos pacientes, no estoy de acuerdo con menospreciarla y desvalorizarla y si estuviera en mí tomar decisiones de cobertura, la incluiría dentro de las prácticas nomencladas. La Wikipedia dice que la homeopatía es considerada una pseudociencia y que se ha descubierto que sus remedios no son más efectivos que los placebos. Parece un comienzo peyorativo, pero gran parte de lo que ofrecemos los médicos a nuestros pacientes es placebo y el límite entre la pseudociencia y la ciencia es tan difuso como el de la medicina que sirve y la que no sirve. Siguiendo para atrás me encuentro con un segundo personaje: la industria farmacéutica. Muchas personas creen en ella, otras descreen totalmente y la detestan y otras, como yo, valoran algunos aspectos y rechazan otros, pero me resulta interesante pensar que la industria farmacéutica y su producción también forman parte de una creencia. Después aparece el personaje del cirujano plástico mediático que seguramente cree en el microtrasplante, así como todas las otras clínicas que encontré en Internet que se dedican a eso. Aparece el sitio web www.recuperarelpelo.com que también funciona como un personaje cuya creencia consiste, aparentemente, en brindar información actualizada y libre de influencias a las personas preocupadas por su calvicie. Aparece el personaje de mi amiga dermatóloga, con sus creencias y sus puntajes acerca de la efectividad de los diferentes tratamientos, y luego (siempre yendo hacia atrás), aparece un personaje que me resulta muy simpático y al cual no me he dedicado todavía y ahora me dan ganas de hacerlo: se trata de Ulrike Blume-Peytavi, la primera autora del artículo sobre la efectividad de los análogos de las prostaglandinas F2 alfa para mejorar la calvicie en jóvenes varones. No la conozco, ni sé nada de ella, la googleo y veo que estudió medicina entre 1980 y 1987 en la Universidad Libre de Berlín, eso significa que se graduó dos años antes de la caída del muro. Me atrae el nombre de esa Universidad y busco información acerca de ella. Es la mayor de las cuatro universidades de Berlín y una de las más grandes de Alemania. Su historia está estrechamente relacionada con la separación del país después de la Segunda Guerra Mundial, ya que se creó en 1948, en el sector occidental, tras numerosos 
enfrentamientos entre docentes y estudiantes con las autoridades comunistas en la Universidad Von Humboldt (que era, en ese entonces, la Universidad más importante de Berlín y había quedado en el sector comunista). Ahora Ulrike trabaja en el Hospital La Charité, uno de los centros de salud más importantes de Berlín y que durante la guerra fría quedó del lado oriental. Me gusta imaginarme a Ulrike en diferentes circunstancias de su vida: puedo imaginarla acompañando a su hijo al jardín de infantes una mañana helada de enero por las calles de Berlín, también puedo imaginarla sentada en su departamento, con los pies apoyados en un banquito y revisando las galeras del libro del cual es primera autora y cuyo título en español es Crecimiento y trastornos del pelo. Finalmente, me la imagino participando del diseño del ensayo clínico cuya publicación hizo que yo diera con ella, me la imagino dando directivas para el reclutamiento de los dieciséis jóvenes voluntarios con calvicie incipiente (ocho recibieron placebo y otros ocho latanoprost) y saltando de alegría junto a su grupo de trabajo tras abrir los sobres (recordemos que el estudio es un doble ciego, placebo, control) y comprobar que el pelo creció más en los que recibieron la droga activa. Me imagino también su alegría cuando le aceptaron el paper en el Journal of the American Academy of Dermatology (JAAD) y lo publicaron en el Volumen 66 , de la entrega 5 , en mayo de 2012 , en las páginas $794-800$. Me imagino que Ulrike no solamente cree en la eficacia del latanoprost (droga que seguramente debe utilizar con sus pacientes, aunque no creo que les cobre ya que me la imagino trabajando full time en La Charité, que es un Hospital Público) sino que se trata de una persona con fuertes convicciones científicas, es decir, una persona que cree profundamente en la ciencia. $Y$ cuando digo esto estoy queriendo decir que Ulrike seguramente está convencida de que el ensayo clínico aleatorizado doble ciego placebo control no solamente representa el sumum de la verdad científica del momento sino que es la pura verdad. El problema que tenemos los médicos que estamos preparados para curar de un paciente, hoy en día, en una sociedad de consumo, es que debemos aceptar que todos nuestros actos están basados en nuestras creencias. $Y$ he aquí la afirmación que me permito hacer, y que seguramente irrite a más de un lector: el hallazgo de Ulrike, la revisión de Young $\mathrm{M}$ Choi (otro personaje de este texto) y el enamoramiento de la "capa" (personaje muy complejo, por cierto) con este tratamiento no son más que creencias. Para muchos lectores esto es muy difícil de aceptar, y de pensar, y a nosotros, los médicos "oficiales", que creemos en la ciencia, nos resulta particularmente desagradable asumir (aceptar) que la ciencia también es una creencia. No aspiro a convencer a nadie, y obviamente podemos entrar en una tautología en la cual alguien podría decir que esa es mi creencia y por supuesto tendrá razón. En relación con la creencia en la ciencia, Nietzsche escribió un breve y hermoso texto que está en el libro La Gaya Ciencia² al que tituló Hasta qué punto también nosotros seguimos siendo píos (aforismo 344, del quinto libro) en el que describe cómo la ciencia, que surge como una oposición a las creencias religiosas, también terminó convirtiéndose en una creencia más, en un dogma. A mí me gusta el modo en el que Nietzsche plantea esto y ahora, si bien me sigue gustando la ciencia, acepto que es una creencia más. Solamente entonces, cuando los médicos aceptamos que la ciencia es una creencia más, podemos aceptar la respuesta que elaboré para mi pregunta, pero reconozco que no es un tema sencillo este de aceptar que la ciencia es una creencia más. El problema con las creencias es que son así, lo que yo propongo solamente, en relación al desafío que representa prepararse para curar de, es que aceptemos que todos nosotros necesitamos de las creencias para actuar, y que las demás personas también, y que a veces las creencias coinciden y otras no.

Estoy llegando al final de mi periplo. Mi entusiasmo me condujo a escribir este ensayo, cuyos ejes han sido el PFPC, el concepto de curar de y las creencias. La revisión del PFPC es posible que les sea útil a algunos colegas que lean este ensayo. La enunciación del concepto de curar de puede abrir, a mi juicio, una nueva perspectiva en el modo en el que miramos y pensamos nuestra práctica. Si podemos relajarnos y asumir que la forma como nos ocupamos de nuestros pacientes, como nos preparamos para curar de ellos, no depende totalmente de nuestra voluntad y a la vez está visceralmente relacionada con nuestras creencias, tal vez podamos iniciar un nuevo camino y dejar atrás las tensiones a las que nos quiere conducir inexorablemente la dualidad metafísica reinante. Todo lo que ocurrió en este ensayo está basado en mis creencias, y eso no lo hace ni peor, ni mejor. Estoy convencido (tengo la ilusión de, creo) que en esta mañana luminosa de abril se produjo un acontecimiento que determinó que yo, habiendo estado preparado para, pudiera curar de Ofelia, y ese sentimiento fue tan fuerte, generó tanto entusiasmo en mí que me puse a escribir, y al hacerlo fueron apareciendo otras creencias. Y fue así como en el texto puede dejarse entrever que a mí no me gusta el modo como atendió a Ofelia la dermatóloga que le indicó finasteride sin indagar acerca de su temor por el cáncer de mama. Y tampoco me gustó el médico de familia que le dijo a mi paciente de 33 años que el finasteride causaba invariablemente problemas sexuales. Y tampoco el modo como la dermatóloga "capa" asustó a mi amigo con los resultados de los análisis. Pero estas críticas no son más que mis creencias (mis perspectivas) y esto nos lleva a plantearnos que estar preparado para curar de no puede ir por el camino de la moral, es decir, no puede entrar en la encrucijada metafísica del bien y del mal. Cada vez va quedando más claro que el concepto de curar de no se dejará asir por nadie, y que así como llega y se va cuando quiere, es completamente libre, está por fuera de toda moral y no se deja someter a las críticas. El desafío que tenemos los médicos que queremos disfrutar del curar de y que nos preparamos para ello es asumir que este concepto implica una creencia, una perspectiva y un gusto, y que juntos fluyen por un río, siempre hacia adelante, en un mundo incierto.

El lector probablemente no recuerde que al comenzar este ensayo dije que la señora Ofelia J, de 82 años, ya había despertado en mí el deseo de tener algo escrito acerca de ella ya que dos meses atrás le pedí que me describiera sus vacaciones mientras yo transcribía lo que me contaba, y que ese texto quedó guardado, dispuesto a aparecer tal vez en algún lado. Ahora ha llegado el momento de que ese pequeño texto aparezca, porque ahora, después de la revisión técnica sobre el PFPC y el desafío teórico al que nos enfrenta la medicina del sorgen y la complejidad de las creencias, quiero volver a la vida real de Ofelia y al vínculo que yo tengo con ella. He aquí el texto:

Médico: - ¿Adónde se va de vacaciones?

Ofelia: - Me voy a Mar del Plata. Tengo una pequeña casita en Punta Mogotes. Me gusta mucho el lugar, o sea que cuando llego allá cambio un poco mi vida, no porque acá esté mal, pero es el aire de mar que me gusta, no porque yo vaya a nadar (porque tengo fobia a meterme en el mar), pero lo disfruto porque voy con mis amigas, que más o menos son de mi misma edad, que son en especial dos con las que yo tengo, digamos, buena comunicación y que son como mis hermanas. Lo disfrutamos porque pensamos las tres de la misma forma sobre nuestras vidas, sobre nuestras cosas, es un mes en el que las tres estamos distinto que acá en Capital, porque acá me encuentro sola, en mi casa, a pesar de que tengo un hijo, pero con ellas tengo un coloquio distinto, digamos, que el que podría tener con mi hijo y familia. Cuando estoy allá nos organizamos, nos levantamos a la misma hora, desayunamos y nos vamos caminando hacia el mar, con nuestra silla, alquilamos una sombrilla y nos quedamos más o menos unas cuatro horas de 
la mañana. Luego regresamos, organizamos el almuerzo, nuestras sobremesas son largas y después nos vamos a hacer nuestra pequeña siesta y cada una de nosotras nos levantamos a la hora que deseamos. Después, a ver, más o menos a la tardecita, salimos fuera de la casa y una toma mate, otra toma el té y nos ponemos a jugar, y si no es eso, charlamos. Eso puede ser algunos días, otros, al atardecer, a eso de las seis de la tarde, nos organizamos y nos vamos al centro, a pasear, al casino, o al teatro. Cuando llega el momento de lo que hemos resuelto, ya sea ir al centro a pasear o a ver una obra de teatro, nos organizamos, ya con las entradas en la mano, y luego del teatro nos vamos a cenar algo.

Médico: - ¿En qué medio de trasporte van a Mar del Plata?

Ofelia: - Nos vamos de puerta a puerta. Es una empresa que nos viene a buscar al domicilio de Capital y nos lleva al domicilio de allá de la casa, es una combi.

\section{Referencias}

1. Heidegger, M. El ser y el tiempo. México. Fondo de cultura económica. 2009.

2. Nietzsche, Friedrich. La gaya ciencia. Madrid: EDAF; 2011. Quinto libro. Nosotros los sin miedo. 344: pág. 293-4.

3. Mc Michael A. Female pattern hair loss (androgenetic alopecia in women); Pathogenesis, clinical features and diagnosis. In: UpTuDate, Hordinsky M. (Ed), UpToDate, Walthman, MA. (último acceso junio 2015).
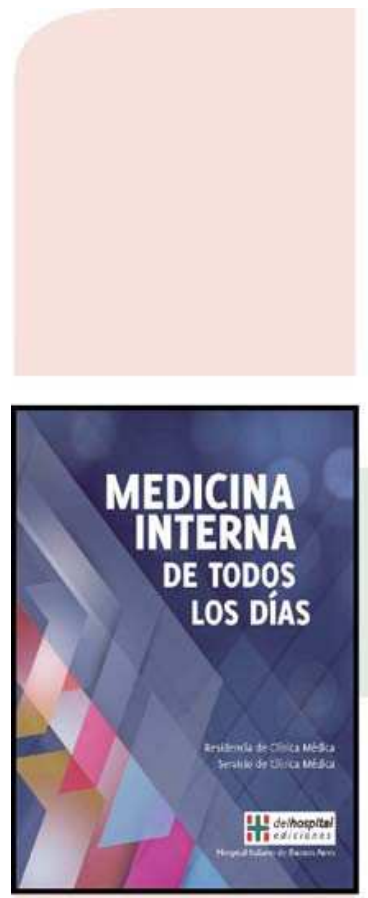

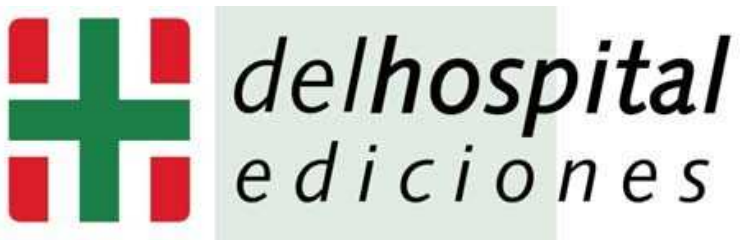

\section{Novedades editoriales}

\section{5}

Medicina interna de todos los días es una herramienta práctica para resolver problemas cotidianos de la sala de internación o las áreas de emergencia presentada en un formato organizado y accesible que facilita la consulta rápida.

Este libro es útil para los médicos clínicos, internistas y otros especialistas que deben resolver problemas clínicos en el ámbito hospitalario.

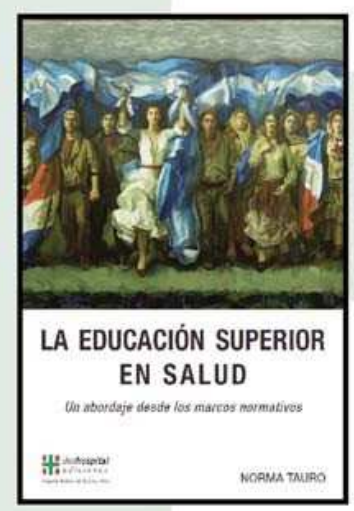

En La educación superior en salud los profesionales de la salud, así como educadores,

legisladores, funcionarios, académicos y profesionales del derecho encontrarán los fundamentos legales que regulan el funcionamiento de las instituciones de la educación superior en salud. Su análisis circunstanciado les permitirá profundizar en el conocimiento fundado y crítico de todas las normativas vigentes, reunidas por primera vez en una obra de excelencia.

Autora: Norma Tauro ISBN 978-987-1639-44-1

Editores: María de las Mercedes Magaz y

Mariano Macaluso

ISBN 978-987-1639-41-0

\section{Consulte todo nuestro catálogo en: www.hospitalitaliano.org.ar/educacion/editorial}

